\title{
MOBBING IN HEALTH CARE INSTITUTIONS
}

\section{MOBING U ZDRAVSTVENIM USTANOVAMA}

\author{
Sofija Dušović
}

\section{Summary}

Health employees represent the second largest group with problems related to various forms of undesirable behavior during the working process among employees - i.e. mobbing. Respecting the data of working environment that suits the emergence of mobbing, the specificity of the work process and the interaction of employees that are presented as higher risk factors for reporting abuse at workplace, we will try to point out the importance of studying mobbing in the health care system. Due to a specific nature of the work of the healthcare workers do (exposure to stressful and traumatic events, more stringent hierarchical structures of employees, exhausting working hours at times, frequent on-call, changing the day/night rhythm, a great responsibility assumed by this workplace) we decided to research this particular activity.

Key words: mobbing, medical workers, health care institutions

\section{Sažetak}

Zaposleni u zdravstvu predstavljaju drugu najveću grupu kod koje je utvrđen niz problema povezanih sa različitim formama nepoželjnog ponašanja u toku radnog procesa među zaposlenima - mobingom. Zahvaljujući podacima o radnoj sredini koja pogoduje nastanku mobinga odnosno specifičnostima radnog procesa i interakcije zaposlenih koji su predstavljeni kao veći faktori rizika za javljanje zlostavljanja na radnom mestu, pokušaćemo da ukažemo na značaj proučavanja mobinga u zdravstvenom sistemu. Zbog specifičnosti radnog angažovanja zdravstvenih radnika (izloženost stresnim i traumatskim događajima, strožije hijerarhijske strukture zaposlenih, nekada iscrpljujućeg radnog vremena, čestim dežurstvima, promenom ritma budnosti, velikom odgovornošću koju pretpostavlja ovo radno mesto) odlučli smo se za istraživanje upravo ove delatnosti.

Ključne reči: mobing, zdravstveni radnici, zdravstvene ustanove

\section{UvoD}

Etimološko značenje reči mobing vodi poreklo iz engleskog jezika i reči to mob koju možemo prevesti kao navaljivanje, nasrtanje. Uz ovaj termin koriste se i brojni drugi kakvi su bullying, work abuse i sl. Jedan od najvećih autoriteta u istraživanju mobinga je nemački psiholog Leymann (1), koji je ujedno i tvorac ovog izraza za određena neprihvatljiva ponašanja na radnom mestu.

Postoje brojne definicije mobinga, i uglavnom sve mobing predstavljaju kao postojanje ponovljenog psihološkog maltretiranja na radnom mestu koje izaziva bespomoćnost i patnju žrtve mobinga. Najcitiranija definicija mobinga je ona koju daje Heinz Leymann (1) po kojoj „mobing ili psihološki teror je neprijateljski i neetički oblik komunikacije na radnom mestu od strane jedne ili više osoba usmeren prema pojedincu koji se usled toga nalazi u stanju bespomoćnosti i nemogućnosti da se odbrani, a sve zbog ponovljenih mobing aktivnosti od strane mobera. Ove aktivnosti su česte (minimum jednom nedeljno) i traju duži vremenski period (minimum šest meseci). Zbog čestog ponavljanja i dugog trajanja neprijateljskog ophođenja dolazi do mentalnih, psihosomatskih i socijalnih posledica."

Rastuća kompetencija zaposlenih u zdravstvenom siste$\mathrm{mu}$, nestabilna ekonomska situacija koja pogađa i ovaj sektor, nesigurnost radnog mesta neki su od pretpostavljenih uzroka pojave mobinga u zdravstvenim ustanovama. Savremeni zdravstveni sistem je izložen brzim i naglim promenama u pogledu zapošljavanja, uslova poslovanja i uopšte radnog angažovanja. Karakteristike savremenih zdravstvenih sistema su sve veća upotreba modernih tehnologija, veliki protok informacija i komunikacije uopšte.

\section{KARAKTERISTIKE MOBINGA}

Psihološko maltretiranje na radnom mestu predstavljeno je aktivnostima čiji sadržaj i intenzitet su često pri početku mobinga na niskom nivou, ali se vremenom potencijal zlostavljanja uvećeva. Autori se uglavnom slažu da su najčešći postupci mobinga zapravo sistematski napadi koje preduzimaju pojedinci ili grupe u cilju izazivanja psihološke i psihosomatske štete kod žrtve, a koje je Leymann (2) prvi svrstao u sledeće aktivnosti:

- napadi na mogućnost komunikacije (ograničavanje ili prekidanje žrtve dok govori, vikanje i ponižavajući gestovi, izbegavanje neverbalne komunikacije sa žrtvom); - napadi na održavanje socijalnih odnosa (žrtva je izolovana, zabranjen je kontakt sa njom, nekada je i fizički udaljena od drugih - u udaljenije delove zgrade, bolnice, fabrike i sl.)

- napadi na ličnu reputaciju (ogovaranje, podsmevanje, vređanje, šale na račun privatnog života, fizičkog izgleda, dodeljivanje ponižavajućih zaduženja)

- napadi na kvalitet rada (stalna kritika i kontrola žrtve, dodeljivanje besmislenih ili degradirajućih, isuviše lakih ili preteških radnih zadataka, često kažnjavanje i nisko ocenjen rad); 
- napadi na psihičko zdravlje (dodeljivanje opasnih i preterano rizičnih zaduženja, pretnja fizičkim nasiljem ili direktno nasilje, izazivanje snažnog stresa, seksualne ponude, uznemiravanje i zlostavljanje).

Podela oblika mobinga uglavnom se izvodi prema kriterijumu odnosa mobera i žrtve, odnosno njihovih uloga koje imaju u radnom procesu. Na taj način neki autori (Kostelić-Martić) (3) razlikuje vertikalni i horizontalni mobing. Vertikalni upućuje na rukovodioce (šefove, direktore, uopšteno pretpostavljene) koji vrše mobing nad nekim od radnika ili grupom podređenih zaposlenih. Horizontalni nastaje između samih radnika koji zauzimaju jednake položaje u radnom procesu. Kostelić-Martić (3) navodi i mogućnost terora nad pretpostavljenim od strane grupe radnika kao jednog od oblika vertikalnog mobinga, ali i smišljenog (strateškog) mobinga u slučajevima kada više rukovodilaca odredi da su neki radnici nepoželjni odnosno da treba otpustiti višak radne snage.

Posledice mobinga su mnogobrojne ne samo po pojedinca, već i za radnu organizaciju, ali i u pogledu društva u celini. Leymann (2) navodi da se one najčešće odnose na psihofizičko zdravlje žrtve, ali i na socijalni život, kao i na ekonomski status. U pogledu uticaja mobinga na radnu organizaciju autor (2) smatra da najviše negativnih posledica izaziva pad produktivnosti radnika, izostanaka sa posla, veći troškovi ustanove zbog zapošljavanja novih radnika, ali i usled eventualnih odšteta koje se moraju isplatiti žrtvama mobinga. Negativne posledice oseća i društvena zajednica koju ova pojava opterećuje uvećavanjem troškova lečenja i uopšte zdravstvenog osiguranja, ali i uvećanjem fondova penzijskog osiguranja.

\section{ZAKONSKA REgULATIVA O MOBINGU U SRBIJI}

Zakon o sprečavanju zlostavljanja na radu donela je Narodna skupština Republike Srbije 26. maja 2010., i on se primenjuje od 4. septembra 2010. Suština ovog zakona je obavezivanje poslodavaca da sprovode zabranu mobinga (bilo koji vid zlostavljanja na radu i u vezi sa radom, a uz to zabranjuje i zloupotrebu prava na zaštitu od zlostavljanja). Zlostavljanje, u smislu ovog zakona je „svako aktivno ili pasivno ponašanje prema zaposlenom ili grupi zaposlenih kod poslodavca koje se ponavlja, a koje za cilj ima ili predstavlja povredu dostojanstva, ugleda, ličnog i profesionalnog integriteta, zdravlja, položaja zaposlenog i koje izaziva strah ili stvara neprijateljsko, ponižavajuće ili uvredljivo okruženje, pogoršava uslove rada ili dovodi do toga da se zaposleni izoluje ili navede da na sopstvenu inicijativu raskine radni odnos ili otkaže ugovor o radu ili drugi ugovor" (4). Ovaj zakon predviđa i obavezu poslodavca da zaposlenog zaštiti od zlostavljanja i da je u tom smislu dužan da obezbedi uslove koji su neophodni za zdravu i bezbednu radnu okolinu i da rad organi- zuje na način kojim se u najvećoj meri sprečava pojava zlostavljanja na radu i u vezi sa radom. S druge strane zaposleni se obavezuje da se uzdrži od ponašanja koja predstavljaju zlostavljanje i ponašanja koja predstavljaju zloupotrebu prava na zaštitu od zlostavljanja, a ukoliko se toga ne pridržava odgovoran je za nepoštovanje radne discipline i povredu radnih dužnosti.

\section{ZAKONSKA REgULATIVA O MOBINGU U SVETU}

Većina evropskih zemalja (zemlje Beneluksa, Skandinavija, Francuska, Švajcarska) imaju zakone protiv zlostavljanja na radnom mestu (mobinga), a prate ih i brojne druge (Italija, Nemačka..) koje imaju zakone o krivičnoj odgovornosti mobera (pojedinca, organizacije) ukoliko dođe do urušavanja psihofizičkog zdravlja i dobrobiti zaposlenih. Kako smo već spomenuli situacija nije drugačija ni u našoj zemlji u pogledu prisustva mobinga kao oblika zlonamernog i neprijateljskog ponašanja prema zaposlenom, kao ni zakonske regulative koja ga prati.

Mobing se uočava u svim sferama radnog angažovanja i kod svih struktura zaposlenih. Ipak, prema European Agency for Safety and Health at Work (5) na osnovu brojnih empirijskih istraživanja prezentovani su podaci koji govore da postoje izvesna obeležja radnih organizacija odnosno radnog procesa koji vode češćoj pojavi mobinga.

Kao rizičnije radne sredine za pojavu mobinga uglavnom se spominju radne organizacije sa strožijom hijerarhijskom strukturom; snažno autoritaranim rukovodećim kadrom; lošom komunikacijom zaposlenih na svim nivoima; dvosmislenim (i) ili konfliktim ulogama u radnom procesu; nemogućnošću napredavanja ili brzim napredovanjem bez zasluga; neodgovarajućim radnim ambijentom; stresnom prirodom posla; iscrpljujućim, predugim radnim vremenom odnosno smenama koje menjaju socijalni ritam. Uz Evropsku agenciju za sigurnost i zdravlje na radu - European Agency for Safety and Health at Work (5) i Evropska fondacija za poboljšanje uslova života i rada - European Foundation for the Improvement of Living and Working Condition (6) daje slična obeležja radne sredine kao mogućeg izvora stresa koji dovode do češće pojave neprihvatliivog ponašanja na radnom mestu odnosno mobinga.

\section{MoBing U ZDRAVSTVENIM USTANOVAMA}

Zahvaljujući podacima o radnoj sredini koja pogoduje nastanku mobinga odnosno specifičnostima radnog procesa i interakcije zaposlenih koji su predstavljeni kao veći faktori rizika za javljanje zlostavljanja na radnom mestu, pokušaćemo da ukažemo na značaj proučavanja mobinga u zdravstvenom sistemu, konkretno mobinga nad zdravstvenim radnicima. Upravo zbog 
Tabela 1. Učestalost mobinga prema profesionalnim delatnostima u EU*

\begin{tabular}{|cc|}
\hline Delatnost & Prisustvo mobinga (\%) \\
\hline Državna uprava i odbrana & $14 \%$ \\
\hline Zdravstvo i prosveta & $\mathbf{1 2 \%}$ \\
\hline Hotelijerstvo i ugostiteljstvo & $10 \%$ \\
\hline Komunikacije i transport & $10 \%$ \\
\hline Trgovina & $9 \%$ \\
\hline Industrija i rudarstvo & $6 \%$ \\
\hline Ekonomija i finansije & $5 \%$ \\
\hline Građevinarstvo & $5 \%$ \\
\hline Elektro i vodosnabdevanje & $3 \%$ \\
\hline Poljoprivreda, šumarstvo i ribarstvo & $3 \%$ \\
\hline
\end{tabular}

${ }^{\star}$ Prema European Foundation for the Improvment of Living and Working Conditions (6)

specifičnosti radnog angažovanja zdravstvenih radnika (izloženost stresnim i traumatskim događajima, strožije hijerarhijske strukture zaposlenih, nekada iscrpljujućeg radnog vremena, čestim dežurstvima, promenom ritma budnosti, velikom odgovornošću koja prati ovo radno mesto) se pretpostavlja da oni predstavljaju drugu veliku grupu zaposlenih po učestalosti mobinga na radnom mestu. Prema podacima koje iznosi Field (7) zaposleni u zdravstvu predstavljaju drugu najveću grupu kod koje je utvrđen niz problema povezanih sa različitim formama nepoželjnog ponašanja $u$ toku radnog procesa među zaposlenima - mobingom. Na prvom mestu prema ovom autoru su zaposleni u prosveti, pre svega nastavnici. Prema podacima Evropske fondacije za poboljšanje uslova života i rada (6) mobing je najprisutniji u državnoj upravi i poslovima odbrane, odmah zatim slede oblasti zdravstva i prosvete.

Međunarodni savet medicinskih sestara (The International Council of Nurses - ICN) definiše zlostavljanje na radnom mestu kao "ponašanje koje ponižava, degradira ili na drugi način označava nedostatak poštovanja prema dostojanstvu i vrednosti pojedinca" (8). Kao najčešći vid maltretiranja na radnom mestu medicinskih sestara autori kakav je Ratner navode lateralno nasilje koje je posledica komunikacijskih neslaganja (9), ili namerno pogrdno ponašanje u vidu širenja laži i kleveta kako navodi Rowell (10).

Uobičajeni primeri maltretiranja na poslu kod poziva medicinskih sestara i lekara su mobing nad novopridošlim sestrama i lekarima (odnosi se na početnike, ali ponekad i na iskusne medicinske sestre i lekare koji menjaju radno okruženje), kao i naspram već zaposlenih, koje nekada i sopstvenim kvalitetima mogu iritirati svoju radnu sredinu. Čak i u situacijama kada je novi zdravstveni radnik vrlo sposoban i obrazovan, odnosno spreman da unese nove veštine u posao, drugo osoblje može negativno reagovati. $U$ toj situaciji kolektiv se oseća neprijatno, pa maltretiranjem određenog zdravstvenog radnika poručuje da „sveznalice“ nisu dobrodošle (9). Često u ovakvim i sličnim situacijama pored horizontalnog prisutan je i vertikalan mobing jer udruženi kolektiv utiče na rukovodeći kadar (na rukovodioce zdravstvene ustanove, načelnike odeljenja, glavne sestre, menadžere u zdravstvu i druga odgovorna lica) sa neosnovanim optužbama, klevetama i sl. o mobiranom zdravstvenom radniku. Kako Rowell (10) navodi najčešće se zdravstveni radnik koji je žrtva mobinga optužuje "da ne radi sve što je potrebno za i oko pacijenata“; „,da nije dobar kakvim pokušava da se predstavi“; „da je aroganatn prema kolektivu i pacijentima jer se pravi da sve zna“; „ne radi sve što mu se kaže i pravi propuste u radu“. Ovo su neki od načina koji podrivaju status zdravstvenog radnika na njegovom radnom mestu, čineći ga žrtvom mobinga (10).

\section{SPECIFIČNOSTI MOBINGA NAD ZDRAVSTVENIM RADNICIMA}

Specifičnost mobinga nad zdravstvenim radnicima je uz pomenute karakteristike i u čestom neprijavljivanju mobinga. Poziv zdravstvenog radnika uopšte predstavljen je imidžom osoba koje važe kao stabilne i snažne u situacijama povećanog pritiska i stresnih situacija, koje staloženo i hrabro podnose ovako težak posao. Neki autori poput Lewis-a (11) po ovom pitanju obaveštavaju o nekim zanimljivim obeležjima mobinga nad zdravstvenim radnicima. Kao neke od specifičnosti spomenuti autor (11) sugeriše da ponašanje zdravstvenih radnika koji su u vrhu hijerarhije (uprava zdravstvene ustanove, načelnici odeljenja, glavne sestre različitih jedinica, odeljenja, klinika) ili drugih rukovodilaca (menadžera u zdravstvu i drugih zdravstvenih saradnika) može biti takvo da zbog ranga i pozicije svoj položaj predstavljaju neprikosnovenim, najznačajnijim, a sebe nezamenljivim i uvek u pravu. Njihovo ponašanje u takvim situacijama je dominantno autoritativno i neempatično u pogledu na kolege nižeg ranga. U ovakvim situacijama mober iziskuje „slepu poslušnost“ i odobravanja, dok sa druge strane koči svaku inventivnost i samostalnost $\mathrm{u}$ donošenju odluka kod podređenih, što su sve moguće klice budućeg sukoba. 
Lewis (11) smatra da ukoliko se ovakvo ponašanje dominantnih figura u radnom životu zdravstvenih radnika toleriše, često dolazi do fenomena prihvatanja ovakve radne atmosfere od strane zdravstvenih radnika nižeg ranga, koji ovu situaciju shvataju kao normu, kao „svakodnevni deo posla; rezultat pozicije u profesionalnoj hijerarhiji; nešto što je deo normalne discipline u ponašanju i radu zdravstvenih radnika". Ovo bi mogao biti jedan od glavnih razloga neobaveštavanja o mobingu, čak i kada su u pitanju višegodišnja neprihvatljiva ponašanja $u$ vidu psihološkog maltretiranja u radnom procesu koji obavljaju zdravstveni radnici.

Populacija zdravstvenih radnika se ne može posmatrati kao homogena grupa zaposlenih, upravo usled različitih poslova koji oni obavljaju u toku radnog angažovanja, kao i zbog raznovrsnosnosti radnih mesta za koje se školuje ovaj kadar.

Možemo pretpostaviti da zdravstveni radnici zaposleni u centrima za zbrinjavanje urgentne patologije, hirurškim klinikama, odeljenjima intenzivne nege, odeljenjima palijativne nege, trpe možda najveći pritisak i izloženi su najvišem nivou tzv. ,izgaranja na poslu“. U tom kontekstu, nekada neočekivani i stresni zadaci pri radnom angažovanju i neprestana potreba dokazivanja u kritičnim situacijama, uključujući i stalno usavršavanje i podizanje nivoa znanja koje ovako delikatan posao iziskuje, mogu uticati na pojavu fenomena kakav je mobing.

Posledice koje izaziva mobing u zdravstvenom sistemu po pojedinca, zdravstvenu ustanovu i društvo uopšte su značajne. Posledice zlostavljanja na radnom mestu se tiču ne samo direktnih žrtava mobinga kod kojih izaziva stres, bolest, ozbiljno narušavanje psihofizičkog zdravlja; već i populacije sa kojom zdravstveni radnici rade. Pacijenti u ovakvim situacijama najčešće ne mogu dobiti adekvatne usluge i negu koju bi zdravstveni sistem trebao da im obezbedi. Spomenimo da i zdravstvena ustanova, ali i čitavo društvo zbog ove pojave mogu imati niz poteškoća. Kao najčešće posledice na globalnom nivou izdvajaju se česta odsustvovanja sa posla i bolovanja; prevremeni odlazak u penziju; radna neproduktivnost i apatičnost $\mathrm{u}$ obavljanju posla; napuštanje posla; troškovi lečenja žrtava mobinga narušenog zdravlja; odštetni zahtevi žrtava mobinga, ali i nezadovoljnih pacijenata na koje loši međusobni odnosi zaposlenih zdravstvenih radnika mogu imati veliki uticaj; neprimeren i loš utisak koji zdravstvene ustanove u ovakvim situacijama ostavljaju na opštu populaciju.

Napomenimo podatak koji daju Lewis i Urmston (12) da je u toku 2000. godine jedno od najnepopularnijih radnih mesta u Velikoj Britaniji bilo upravo radno mesto medicinske sestre. Usled toga konkursi koje je ova država raspisivala za prijem u radni odnos za mesto medicinske sestre su bili objavljivani širom EU radi zadovoljavanja potreba zdravstvenog sistema Velike Britanije za ovim profilom. Profesija medicinskih sestara je jedna od tradicionalno ženskih profesija u kojoj dominira snažna hijerarhija, a sam posao je "pomagačkog" karaktera što ga po nekim autorima svrstava u vrh skale profesija u kojima su mobing i slična traumatizacija česta pojava (13-15).

Prema podacima istraživanja Evropske fondacije za poboljšanje uslova života i rada (European Foundation for the Improvement of Living and Working Conditions) (6) o distribuciji mobinga prema različitim delatnostima, procenat koji je za našu temu najznačajniji je upravo prisustvo mobinga u zdravstvu (12\%) što je u ravni sa procentom utvrđenim u prosveti, a jedino nešto niže od onog zabeleženog u državnoj upravi i administraciji. Sve ostale delatnosti koje su analizirane (trgovina; ugostiteljstvo; prevoz i komunikacije; industrija; finansijski sektor; građevinarstvo; komunalne usluge; transport; poljoprivreda i ribarstvo) ispod su zabeleženog procenta mobinga u zdravstvu.

\section{ZAKLJUČAK}

Mobing je sveprisutan fenomen u radnom angažovanju savremenog čoveka i upozorava na veliku društvenu i psihološku važnost samog radnog mesta za pojedinca. Naročito se ističe rastuća evidencija mobinga među zdravstvenim radnicima.

Na osnovu izloženog možemo zaključiti da mobing u zdravstvenom sistemu, konkretno mobing nad zdravstvenim radnicima je prisutna i zabrinjavajuća pojava. Zdravstveni radnici izloženi su stresu i izgaranju na poslu (burning out) zbog velikog broja pacijenata, neprekidnog pružanja zdravstvene nege najtežim bolesnicima, velike odgovornosti i stručnosti koje ovaj poziv zahteva, čestim dežurstvima koja remete ritam budnosti, ali i strogom hijerahijskom organizacijom i disciplinom koja se od njih očekuje.

\section{Literatura}

1. Leymann H., The Mobbing Encyclopedia, Available at: http://www. leymann.se/English/1200.HTM

2. Leymann H. Mobbing and Psychological Terror at Workplaces. Violence and Victims. 1990; 5 (2):119-126.

3. Kostelić-Martić A. Mobing: psihičko maltretiranjena radnom mjestu. Zagreb: Školska knjiga, 2005.

4. Zakon o sprečavanju zlostavljanja na radu. Službeni glasnik RS, 2010; broj 36/10.
5. European Agency for Safety and Health at Work, Available at: European Foundation for the Improvement of Living and Working Conditions. Available at: www.agency.osha.eu.int

6. European Foundation for the Improvment of Living and Working Conditions. Available at: www.eurofound.eu.int.

7. Field T. Bully in Sight: How to predict, resist, challenge and combat workplace bullying - Overcoming the silence and denial by which abuse thrives.London: Success Unlimited, 1996. 
8. International Council of Nurses. Guidelines on coping with violence in the workplace. Geneva:ICN, 2004.

9. Ratner T. Communication in the OR. Nursing Spectrum. 2006; 23:10-11.

10. Rowell P. Lateral Violence: Nurse Against Nurse. Available from: Lewis, M. Bullying in nursing. Nursing Standard. 2001; 15 (45): 39-42.

11. Lewis M. Bullying in nursing. Nursing standard. 2001; 15 (45): 39-42.

12. Lewis M, Urmston J. Flogging the dead horse: the myth of nursing empowerment? Journal of Nursing Managment. 2000; 8(4):209-213.
13. Godin M. Bullying, worker's health, and labour instability. J. Epidemiol. Comm. Health. 2004; 258-259.

14. Durmus SC, Topcu I, Yildirim A. Mobbing Behaviors Encountered by Nurses and Their Effects on Nurses. International Journal of Caring Sciences. 2018; 11 (2): 905-913.

15. Castronovo MA, Pullizzi A, Evans S. Nurse Bullying: A Review And A Proposed Solution. Nursing Outlook. 2016; 64(3): 208-214. 